\title{
FORA DE CENA: A INVISIBILIDADE DOS TERRITÓRIOS QUILOMBOLAS CAPIXABAS NA IMPRENSA CAPIXABA
}

\author{
Girley Vieira da Silva ${ }^{1}$ \\ Prof $^{a}$ Dr $^{a}$ Patrícia Gomes Rufino Andrade ${ }^{2}$
}

\section{RESUMO}

A forma como a mídia aborda questões relacionadas aos direitos das minorias deve ser objeto de preocupação dos pesquisadores da área, sobretudo quando se considera a capacidade que os meios de comunicação têm de interferir na esfera pública e social. Este artigo, particularmente, analisa o apagamento e o silenciamento da política de titulação de territórios quilombolas no jornal A Gazeta em um período de 15 anos a partir da promulgação da Constituição Federal (1988-2003). Tendo como suporte teórico-metodológico as categorias interdiscurso [ou memória do dizer] e silêncio, da escola francesa de Análise do Discurso, foi possível constatar a invisibilização de comunidades remanescentes de quilombos na cobertura realizada por esse jornal, que é um dos impressos de maior tiragem do Espírito Santo e de maior legitimidade na elite capixaba. O periódico ainda se limitou, no parco espaço destinado a essa minoria, a tratar de questões ligadas à cultura e a problemas sociais locais, passando ao largo de assuntos de real interesse daquelas comunidades como o direito constitucional ao reconhecimento e à demarcação de seus territórios.

Palavras-chave: Quilombolas. Jornalismo. Poder. Discurso. Silenciamento.

\begin{abstract}
The media's approach to issues related to minority rights should be a matter of concern to researchers in the area, especially when considering the ability of the media to interfere in the public and social spheres. This article, in particular, analyzes the erasure and silencing of the politics of titling of quilombolas territories in the newspaper A Gazeta in the period of 15 years from the promulgation of the Federal Constitution (1988-2003). Having as a theoretical and methodological support the interdiscourse categories [or memory of the say] and silence, of the French school of Discourse Analysis, it was possible to verify the invisibilization of communities remaining quilombos in the cover realized by this newspaper, that is one of the printed of greater Drawing of the Holy Spirit and of greater legitimacy in the Espírito Santo elite. The journal was still limited, in the small space destined to this minority, to deal with issues related to local culture and social problems, moving away from matters of real interest of those communities as the constitutional right to the recognition and demarcation of their territories.
\end{abstract}

Keywords: Quilombolas. Journalism. Power. Speech. Silencing.

\footnotetext{
${ }^{1}$ Mestrando do Programa de Pós-graduação em Comunicação e Territorialidades da Universidade Federal do Espírito Santo (Poscom-Ufes). E-mail: girleyvs@ @otmail.com.

${ }^{2}$ Doutora em Educação; Professora Adjunta do Departamento de Educação, Política e Sociedade (Ufes) e do Poscom-Ufes; Coordenadora do Núcleo de Estudos Afro Brasileiros (Ufes). E-mail: patiruf.pr@gmail.com.

CSOnline - Revista Eletrônica de Ciências Sociais, Juiz de Fora, n. 23 (2017), pp. 100-119.
} 


\section{INTRODUÇÃO}

A forma racista e marginalizada como as minorias étnicas são tratadas no Brasil guarda relações de historicidade com convenções sociais que precedem a própria chegada dos europeus ao país. A ideologia do sangue "puro", como critério de classificação social estabelecido pelo Estatuto-Setencia de Toledo ${ }^{3}$ (1449) na Península Ibérica, só para ficar em um exemplo entre outros possíveis, foi trazida de além-mar nas mesmas caravelas em que estavam os colonizadores.

No caminho percorrido desde a invasão do Brasil pelos Portugueses até os dias atuais essa perspectiva segregacionista eurocêntrica perpetuou-se no âmago das classes que detiveram [e detêm] o poder no país. E o modus operandi dessa ideologia, conhecido de todos nós - extermínio, exploração e marginalização das minorias étnicoraciais -, resultou na construção da nação brasileira que ainda hoje exibe as marcas da desigualdade forjadas ao longo desse trajeto. Faz mister destacar que essa dominação materializada no racismo estrutural não está presente somente na diferenciação de direitos sociais e humanos, tais como educação, saúde, moradia, ascensão social etc. entre os cidadãos, mas também no acesso aos instrumentos de produção e propagação do discurso.

E como o exercício do poder está intimamente ligado às práticas comunicacionais e, consequentemente, à produção e disseminação de discursos, a reparação dos danos causados por esse racismo estrutural e a construção de uma sociedade que coloque todas as pessoas em condições de igualdade passam também pela disputa no campo produção de sentidos, especialmente no campo da comunicação de massa que, para Manuel de Castells (2015), seria o espaço com maior potencial de atingir e mudar a sociedade. Para ele:

\footnotetext{
O poder é mais do que comunicação e a comunicação é mais do que poder. Mas o poder depende do controle da comunicação, assim como o contrapoder depende do rompimento desse controle. E a comunicação de massa, a comunicação que potencialmente atinge a sociedade como um todo, é moldada e administrada por relações de poder, tem raízes nos negócios da mídia e nas políticas de Estado. O poder da comunicação está no âmago da estrutura e da dinâmica da sociedade (p.21).
}

\footnotetext{
${ }^{3}$ Essa "lei" tinha por objetivo impedir que os recém-convertidos à Fé Católica e considerados de "sangue infecto" (judeus, mouros e negros) pudessem ocupar cargos é considerado um dos primeiros estatutos de "limpeza racial" na Península Ibérica (VAN DIJK, 2008, p. 75).

CSOnline - Revista Eletrônica de Ciências Sociais, Juiz de Fora, n. 23 (2017), pp. 100-119.
} 
Embora as tecnologias disponíveis atualmente favoreçam o aparecimento de novas vozes e novas versões, e elas têm emergido em diversos espaços de contrapoder a partir da prática do midiativismo, por exemplo, é fato que as construções discursivas presentes na mídia não favorecem as minorias, pois há o predomínio do discurso hegemônico (VAN DIJK, 2008).

Nessa esfera, um campo em especial merece destaque ao tratarmos da propagação de discursos sobre as minorias: o campo do jornalismo. Isso porque a imprensa apresenta condições muito particulares para promover o processo de solidificação de ideologias, de interferência na formação da opinião pública e de ressignificação do sentido de palavras no âmbito do imaginário social. E como esse campo tem priorizado as perspectivas do capitalismo de mercado - como o consumismo, o individualismo e a competição, em detrimento das culturas e saberes tradicionais (MORAES, 2013) - , justifica-se a partir dessa constatação a realização de estudos que se ocupem da temática aqui sugerida.

Segundo André Ricardo Nunes Martins (2016), as minorias estariam enfraquecidas nesse jogo do poder, no processo de disputa política. O discurso da grande imprensa, na opinião desse autor, excluiu ou minimiza a visibilidade dos grupos étnicos minoritários, colaborando no fortalecimento e na reprodução do racismo estrutural na medida em que

[...] não prioriza questões de interesse dessas minorias ou vincula-os sistematicamente à falta de instrução, à pobreza, à violência, à perturbação da ordem etc. Sendo a mídia em geral e a imprensa em particular uma arena de luta política de primeira grandeza, as minorias estão em desvantagem no processo de participação política (p. 30).

E são justamente os fenômenos manifestados nessas práticas discursivas que compõem o objeto de estudo da pesquisa que desenvolvemos no âmbito do Programa de Pós-graduação em Comunicação e Territorialidades da Universidade Federal do Espírito Santo a qual investiga o posicionamento da imprensa capixaba na cobertura do processo de titulação de comunidades quilombolas. O presente artigo, que apresenta parte inicial dos resultados da pesquisa, por sua vez, analisa o discurso veiculado em jornal de grande circulação entre 1988 e 2003 sobre a titulação de territórios quilombolas na perspectiva do conceito de política do silêncio proposto pela autora Eni Puccinelli Orlandi (2007).

Para a realização dessa investigação, o trabalho está organizado da seguinte maneira: a primeira parte, que contempla o suporte teórico metodológico, apresenta um 
tópico específico sobre as comunidades e o direito à titulação dos territórios quilombolas; um outro discute o campo jornalístico, englobando seu funcionamento e as respectivas teorias que dão conta da forma como os discursos são organizados e produzidos pela imprensa; e, por último, um tópico que trata das teorias do discurso. A segunda parte é composta pela análise do corpus selecionado e as considerações finais sobre os resultados dessas avaliações.

\section{A LUTA PELO RECONHECIMENTO}

Desde o período da escravização, conflitos de diferentes naturezas permeiam as relações sociais entre a população negra e grupos ideologicamente brancos no Brasil e no Espírito Santo. E conforme aponta Simone Raquel Batista Ferreira (2010), esses embates consolidam identidades distintas que podem ser verificadas, especialmente quando se observa as respectivas formas de relação com o território e as diversas práticas que passaram a coexistir nesse espaço.

É fato que o Estado brasileiro, em termos de legislação que abarcasse direitos, demorou a reconhecer a presença de comunidades quilombolas neste país, mesmo passados mais de 100 anos da abolição formal da escravidão. Porém, a inserção do Art. 68 no Ato das Disposições Constitucionais Transitórias (ADCT) da Constituição Federal $(\mathrm{CF})^{4}$ e a edição de outros instrumentos normativos sequer foram suficientes para a consolidação desse direito. Segundo dados oficiais do Instituto Nacional de Colonização e Reforma Agrária (Incra) - órgão responsável pela execução dessa política pública prevista na CF - das cerca de três mil comunidades quilombolas espalhadas pelo país apenas pouco mais de 150 obtiveram a titulação de suas áreas.

Todavia, a batalha na esfera estatal não é o único desafio experienciado por essa minoria. A disputa no campo discursivo também impõe uma série de obstáculos a essas comunidades, que na luta pela titulação do território vivenciam constantes conflitos no processo de ressignificação de sua própria existência em sentido cultural, econômico, social, político etc. Segundo Osvaldo Martins Oliveira (2011):

Os quilombos no Brasil, em diferentes períodos da história, têm enfrentado embates visando obter autonomias, primeiro em relação aos regimes escravocratas e, depois, diante dos grandes empreendimentos econômicos que sucederam tais regimes. $\mathrm{Na}$ análise de situações sociais de conflitos e

\footnotetext{
4 "Art. 68. Aos remanescentes das comunidades dos quilombos que estejam ocupando suas terras é reconhecida a propriedade definitiva, devendo o Estado emitir-lhes os títulos respectivos" (BRASIL, 1988).
}

CSOnline - Revista Eletrônica de Ciências Sociais, Juiz de Fora, n. 23 (2017), pp. 100-119. 
suas influências nos processos políticos de formação da consciência quilombola, se levássemos em conta os estudos sobre a existência dos primeiros quilombos, como foi o de Palmares (CARNEIRO, 1988; MOURA, 1987), estaríamos diante de uma situação na história brasileira, com mais de 300 anos de combates, resistências e negociações (p. 143).

A construção negativa e esvaziada do sentido de quilombo possui diversas interseções com a narrativa sobre negro e a escravidão no Brasil. Isso porque a historiografia construída e disseminada sobre os escravizados foi contaminada pelo o que o professor Carlo Ginzburg (2002) denomina de relações de forças, as quais teriam papel fundamental na decisão dos rumos no processo de construção do ponto de vista da realidade, ou seja, na elaboração retórica da história. Na opinião desse autor, os pontos de vista construídos na narrativa histórica podem ser seletivos e parciais.

Para se evitar equívocos como aqueles cometidos na interpretação da historiografia produzida sob a ótica das classes hegemônicas, o autor recomenda que se escove a história ao contrário, lendo “[...] os testemunhos às avessas, contra as intenções de quem os produziu. Só dessa maneira será possível levar em conta tanto as relações de força quanto aquilo que é irredutível a elas” (GINZBURG, 2002, p. 43).

E essa batalha de ressignificação enfrentada pelas comunidades quilombolas e a construção de sua própria identidade enquanto grupo étnico ${ }^{5}$ na contemporaneidade passa, especialmente, pela desconstrução do mito da democracia racial no Brasil. Essa mudança semântica, na perspectiva de van Dijk (2008), deve incluir a interpretação desse mito como uma forma de racismo racial e ideológico materializado na desigualdade no acesso a bens materiais e simbólicos.

Segundo o linguista holandês, é por meio dos diversos eventos comunicativos, em especial por meio da mídia, que a maioria da sociedade apreende o racismo estrutural, conduzindo-a aos posicionamentos contrários aos direitos das minorias como a titulação de territórios quilombolas. Para van Dijk (2008), a compreensão que a sociedade detém sobre as minorias é

[...] formulada, mais ou menos explicitamente, em inúmeras conversações, histórias, reportagens de jornais, livros didáticos e discurso político. É também sobre essa base que as pessoas formam suas próprias opiniões e atitudes, e, a menos que haja boas razões para desviar do consenso do grupo,

\footnotetext{
${ }^{5}$ Este trabalho adota o conceito proposto por Barth (1969, apud OLIVEIRA, 1976, p. 2) para quem “[...] grupo étnico designa uma população que: a) se perpetua principalmente por meios biológicos; b) compartilha de valores culturais fundamentais, postos em prática em formas culturais num todo explícito; c) compõem um campo de comunicação e interação; d) tem um grupo de membros que se identifica e é identificado por outros como constituinte de uma categoria distinguível de outras categorias da mesma ordem".
}

CSOnline - Revista Eletrônica de Ciências Sociais, Juiz de Fora, n. 23 (2017), pp. 100-119. 
a maior parte dos membros reproduzirá o status quo étnico e adquirirá ideologias dominantes que os legitime (p. 73).

Nessa esteira, os quilombos, sob o olhar das mesmas lentes que distorceram a identidade do negro escravizado, foram retratados como uma espécie de monumento cultural exótico que ajudava a compor no imaginário das classes dominantes o mito da democracia racial. Tal perspectiva, segundo OLIVEIRA (2016), começou a ser transformada somente a partir da publicação da Constituição Federal de 1988.

$\mathrm{Na}$ verdade, ao contrário do que permeia ainda o imaginário de parte da sociedade brasileira, os quilombos não estavam isolados e desconectados do tecido social. Existindo desde o início do processo de escravização no Brasil como forma de luta, resistência, organização social e constituição de identidade cultural, essas estruturas mantinham relações com as estruturas socioeconômicas ao seu redor ou nas senzalas.

O pesquisador João Marques da Silva (2015) defende que os quilombos do passado e as comunidades que atualmente mantém a ligação cultural e histórica com essas raízes (os quilombos modernos), não devem ser vistos como sobras ou lembranças. Esses grupos étnicos, caracterizados especialmente pela sua relação intensa com o território e pela sua territorialidade diferenciada, representam um "modelo de resistência ao sistema escravista vigente" - que tiveram sua imagem distorcida para evitar que se criasse entre os negros uma identificação com o seu passado de luta e organização social e política ativo.

Além de cumprir esse papel político, os territórios quilombolas foram fundamentais, segundo Patrícia Gomes Rufino Andrade (2007), para a preservação da cultura negra:

\footnotetext{
À margem da sociedade e da cultura, aos territórios negros coube a preservação da cultura negra, transformando-a durante as gerações, mas, de certa forma ampliando sua difusão entre as comunidades, embora, em muitos casos, sendo reconhecida como "coisas do povo", enfatizando a cultura popular e, assim, desenraizada dos padrões europeus, não se encaixando nos padrões hegemônicos, mas nem por isso deixando de se expressar e reivindicar suas formas de poder (p. 76).
}

No Espírito Santo, a exemplo do que ocorreu em diversas partes da América onde houve escravidão, os escravizados reagiram a essa condição e promoveram movimentos políticos em busca da autonomia que redundaram na retomada de saberes e contato com lembranças de seu continente de origem. O resultado desse processo, segundo Oliveira (2011, p. 142), foi o surgimento de “[...] diversos agrupamentos, entre 
eles os quilombos, que vêm retomando e transmitindo memórias, saberes e referências culturais, para demarcar modos de vida comunitários em seus territórios”.

O governo da então província do Espírito Santo no século XIX, em função do número crescente de quilombos organizados, os quais eram considerados como ameaças pelo Estado, organizou companhia de guerrilhas para combatê-los. O acervo documental datado de 1710 já ressaltava a diversidade dessas comunidades. Segundo o pesquisador Cléber Maciel (1994, p. 47), em 1823, por exemplo, “[...] moradores brancos de São Mateus fizeram reclamação ao governo alegando que lá existiam muitos quilombos".

Graças a iniciativas de revisão historiográfica, conforme prescreveu Ginzburg (2002), realizadas por pesquisadores de diferentes áreas, entre os quais o professor Oswaldo Martins de Oliveira (2011), é possível estabelecer a conexão entre comunidades quilombolas existentes atualmente no Espírito Santo com os quilombos formados durante e depois do período escravagista no Brasil. Assim:

\footnotetext{
Pelo que revelam os dados documentais, em alguns distritos e vilas, como Viana e São Mateus, os quilombos, apesar da perseguição policial, resistiram por cerca de 40 anos. Uma interpretação desses dados é que existe a possibilidade de pessoas terem nascido e crescido nos quilombos sem conhecer a escravidão. Em algumas localidades do então distrito de Viana, [...], havia quilombo em 1846 (com número elevado de integrantes) e em 1885, como, por exemplo, em Araçatiba, onde ainda hoje existe uma comunidade quilombola. Da mesma forma que, no norte do Espírito Santo, nos atuais municípios de São Mateus e Conceição da Barra, existiram vários quilombos no século XIX e continuam existindo hoje cerca de 30 comunidades que se definem como tais, como são os casos do Bairro Quilombo Novo em Sant'Ana, Linharinho, Córrego dos Pretos e outras localidades do grande território quilombola do Sapê do Norte (OLIVEIRA, 2011, p. 147).
}

Conforme ressaltado anteriormente, a publicação do artigo 68 do Ato das Disposições Constitucionais Transitórias (ADCT) representou um marco importante para essas comunidades tradicionais. Entretanto, foram necessários mais de sete anos para que essa lei entrasse na agenda pública nacional. Conforme salienta o pesquisador José Maurício Andion Arruti (1997, p. 7), “[...] o 'Artigo 68' ficou sem qualquer proposta de regulamentação até 1995, quando (então associado às festividades pela memória de Zumbi de Palmares) ganha importância e passa a ser alvo de debates e reflexões em âmbito nacional”.

Em 1992, explica Simone Rita dos Santos (2014), ocorrem as primeiras tentativas do Ministério Público Federal de aplicar o referido artigo 68 na comunidade do Rio das Rãs, na Bahia, mas a justiça não aceitou a proposta do parquet e indeferiu a causa. Em 1995, a senadora Benedita da Silva (PT/RJ), do movimento negro urbano, e o 
deputado Alcides Moderno (PT/BA) apresentam projetos, no Senado Federal e na Câmara dos Deputados, respectivamente, com o objetivo de regulamentar o dispositivo constitucional. Porém, somente em 10 de setembro de 2001, o Governo Federal toma a primeira medida nesse sentido, com a publicação do Decreto n. 3.912.

Contudo, tal instrumento restringiu o alcance do texto constituicional, segundo Santos (2014). Para essa autora, foi somente com a publicação do Decreto n. 4.887/03, que cancelou o anterior e estabeleceu a Política Nacional de Atendimento às Comunidades Quilombolas, que a expectativa dos beneficiários, ao menos em termos de proposta, pode ser atendida. De acordo com ela:

\begin{abstract}
A nova regulação administrativa apresentou avanços, dentre eles, a adoção de uma conceituação de comunidade e de terra de quilombo fundamentada no critério de autoidentificação, da possibilidade de desapropriação de propriedades incidentes em terras de quilombos quando o necessário, e da atribuição de competência de condução do processo ao Incra. O novo governo, representado pelo PT, mostra uma mudança na condução das políticas governamentais decorrentes da eleição presidencial de 2002 (SANTOS, 2014, p. 64).
\end{abstract}

E mesmo sem os direitos dos povos quilombolas terem sido concretizados, somente a possibilidade de modificação na estrutura social e fundiária por meio das propostas de regularização dos territórios resultantes da aplicação desse decreto foi suficiente para a emergência de questionamentos jurídicos e étnicos, materializados pela reação dos grupos ideologicamente contrários a essa política afirmativa. No olhar de Oliveira (2016) essa reação tem relação com a disputa por terras novas as quais, na ótica racista, devem estar nas mãos de quem tem "capacidade" de gerenciá-las:

\footnotetext{
A própria contrariedade ruralista em relação à titulação quilombola remete à disputa por "terras novas" para expansão do agronegócio, haja vista que, de Nova Venécia, os descendentes de italianos passaram a expandir seus negócios econômicos e políticos para São Mateus e Conceição da Barra. O contraponto desse processo é o ambiente de conflito e competição por direitos à terra que o grupo intitulado Movimento Paz no Campo (MPC) impôs ao pleito quilombola [...] (p. 131).
}

Em meio a essa reação, a imprensa produziu matérias com abordagem de questões em torno da temática. Para entender o contexto de produção do discurso jornalístico, realizaremos nas seções a seguir discussões sobre a relação entre o campo do jornalismo e a produção de discurso.

\title{
O CAMPO DO JORNALISMO
}

CSOnline - Revista Eletrônica de Ciências Sociais, Juiz de Fora, n. 23 (2017), pp. 100-119. 
O processo de produção do discurso veiculado pelo jornalismo é complexo e envolve diferentes atores/agentes. Para subsidiar a busca pela compreensão dessa dinâmica, este trabalho utiliza-se do conceito de campo proposto por Pierre Bourdieu (1997; 2000; 2003). Para esse autor, campo seria um espaço simbólico onde disputas e tensões ocorrem em dada estrutura na qual agentes distintos, em busca de capital simbólico, travam batalhas com o fito de ocupar boas colocações nesse espaço.

Nesse sentido, dada a complexidade desse campo e a constatação de que o jornalismo enquanto prática social envolve muitas interações (dentro e fora do próprio campo), recorremos ao conceito de newsmaking para tentar rastrear alguns aspectos envolvidos nessa prática. Importante ressaltar que esse conceito credita uma certa independência ao jornalismo como processo comunicacional em relação a outros campos, hipótese já contestada no meio acadêmico. Bourdieu (1997), ao contrário dessa visão autônoma, ressalta a capacidade que o jornalismo tem de influenciar outros campos importantes da vida social sob a ótica do mercado que dita as regras das relações de força que determinam a prática noticiosa.

$\mathrm{O}$ autor sugere que se observe a

[...] influência que os mecanismos de um campo jornalístico cada vez mais sujeito às exigências do mercado (dos leitores e dos anunciantes) exercem, em primeiro lugar sobre os jornalistas (e os intelectuais-jornalistas) e, em seguida, e em parte através deles, sobre os diferentes campos de produção cultural, campo jurídico, campo literário, campo artístico. Trata-se então de examinar como a restrição estrutural exercida por esse campo, ele próprio dominado por pressões do mercado, modifica mais ou menos profundamente as relações de força no interior dos diferentes campos, afetando o que aí se faz e o que aí se produz [...] (BOURDIEU, 1997, p. 101).

O que interessa a este estudo no bojo dos princípios do newsmaking, a exemplo do que ressaltam os autores Antônio Hohlfeldt, Luiz C. Martino e Vera Veiga França (2005), é a colaboração dessa teoria para a compreensão do processo de produção de notícias. É possível identificar como participantes desse processo, segundo a perspectiva de Molotch e Lester, três categorias de agentes internos e externos ao campo jornalístico:

a) os promotores de notícia (news promotors), definidos como aqueles indivíduos e os seus associados que identificam (e tornam assim observável) uma ocorrência especial; b) os news assemblers, definidos como todos os profissionais que "transformam perceptível um cojunto finito de ocorrências promovidas em acontecimentos públicos através da publicação ou da radiodifusão" (Molotch e Lester, 1974/1993:38); e c) os consumidores de notícias (news consumers), definidos como aqueles que assistem "a 
determinadas ocorrências disponibilizadas como recursos pelos meios de comunicação social" (MOLOTCH e LESTER, 1974, apud TRAQUINA, 2005, p. 21).

Mesmo tendo essa capacidade de interferir em diversos campos e ao mesmo tempo sofrer interferências diversas no seu processo produtivo, o campo do jornalismo procura ressaltar uma certa independência, conforme a perspectiva do newsmaking anteriormente ressaltada. Para dar sustentação a esse pressuposto, buscando credibilidade junto ao seu público consumidor, essa teoria estabelece algumas premissas norteadoras.

Seriam essas premissas as responsáveis por impingir ao conteúdo publicado o "selo de objetividade" e, para alguns, também o "selo de imparcialidade". Essas convenções, segundo Mauro Wolf (1987), foram criadas, inclusive, para que o meio se precavesse da crítica do público:

[...] Há restrições ligadas à organização do trabalho, sobre as quais se criam convenções profissionais «que determinam a definição de notícia, legitimam o processo produtivo, desde a utilização das fontes até a seleção dos acontecimentos e às modalidades de confecção, e contribuem para se precaver contra as críticas do público» [...] (p. 168).

Essas convenções são chamadas pelos teóricos do newsmaking de critérios de noticiabilidade, que constituem um conjunto de requisitos para que fatos e eventos sejam transformados em notícias. Conforme explica Wolf (2003), a teoria que trata desse fenômeno no campo do jornalismo contempla vários fatores que determinariam a presença [ou ausência] de dados discursos na imprensa. Isso apresentado tanto de forma subliminar ou de maneira ostensiva em seus conteúdos editoriais.

$\mathrm{Na}$ visão desse autor do campo da teoria do jornalismo, a noticiabilidade seria constituída pelo “[...] complexo de requisitos que se exigem para os eventos - do ponto de vista da estrutura do trabalho nos aparatos informativos e do ponto de vista do profissionalismo dos jornalistas -, para adquirir a existência pública de notícia" (WOLF, 2003, p. 194).

Se o campo do jornalismo ao tempo em que cria "regras" para instituir um grau de objetividade e imparcialidade na sua prática também sofre uma série de interferências de outros campos, especialmente do mercado, pois é formado por empresas privadas que visam ao lucro, a análise dos materiais veiculados no jornal $\mathrm{A}$ Gazeta sobre as comunidades quilombolas torna-se um grande desafio. E para vencer 
esse desafio este trabalho busca suporte teórico-metodológico na escola francesa de Análise do Discurso, sobre a qual passamos a discorrer.

\section{O DITO PELO NÃO-DITO: AS DIVERSAS FORMAS DE DISCURSO}

Os veículos de comunicação são portadores de imaginários sociais que têm influência sobre as opiniões do público. Patrick Charaudeau (2006) acredita que a imprensa consegue inserir o cidadão em um mundo em que não é possível se distinguir a realidade da ficção, pois o campo jornalístico é capaz de apresentar

[...] uma espécie de 'verdade verossímil', que faz fundirem-se os dados da ficção na ilusão do autêntico por meio de uma narrativa que constrói seu próprio ideal, fazendo comércio de nossos imaginários (CHARAUDEAU, 2006, p. 285).

A narrativa mencionada na citação do autor é materializada por meio da linguagem, a qual não deve ser vista como uma entidade abstrata. Necessariamente, segundo Helena H. Nagamine Brandão (2002), a linguagem apresenta-se como um lugar em que a ideologia se manifesta concretamente, em que o ideológico, para se objetivar, precisa de uma materialidade. Para a autora, ela configura-se em lugar privilegiado de manifestação da ideologia, da disseminação de ideias e ideais de determinados grupos. Nesse sentido, o

[...] discurso não constitui um universo de signos que serve apenas como instrumento de comunicação ou suporte de pensamento; a linguagem enquanto discurso é interação, e um modo de produção social; ela não é neutra, inocente e nem natural, por isso o lugar privilegiado de manifestação da ideologia (BRANDÃO, 2002, p. 11).

Portanto, apesar de tentar aparentar uma suposta imparcialidade e objetividade, tendo como base argumentos como aqueles apresentados no âmbito do newsmaking, o texto jornalístico, assim como toda linguagem, veicula discursos os quais estão interligados a determinadas ideologias.

Dessa forma, a busca pela identificação dessas nuances extralinguísticas serão realizadas a partir dos pressupostos da escola francesa de Análise do Discurso (AD). Essa disciplina nasceu, justamente, da

[...] necessidade de superar o quadro teórico de uma linguística frasal e imanente que não dava conta do texto em toda sua complexidade. A análise do discurso volta-se para o "exterior" linguístico, procurando apreender como no linguístico inscrevem-se as condições sócio-históricas de produção (BRANDÃO, 2002, p. 103). 
A este propósito, consideramos que a construção do discurso perpassa uma série de relações sociais e históricas. De acordo com a AD, o discurso resultaria de um processo de construção simbólica, sendo os sentidos constituídos, evidenciados e inscritos nos sujeitos por meio de uma relação com os sentidos já postos em funcionamento ou não. Nessa dinâmica, a ausência ou o silêncio também colabora na construção de sentido. Para Michel Pêcheux (1990):

Todo discurso é o índice potencial de uma agitação nas filiações sociohistóricas de identificação, na medida em que ele constitui ao mesmo tempo um efeito dessas filiações e trabalho (mais ou menos consciente, deliberado, construído ou não, mas, de todo modo, atravessado pelas determinações inconscientes) de deslocamento no seu espaço (p. 56).

Partindo-se dessa perspectiva, o discurso seria uma unidade aberta relacionando-se a outros existentes, possíveis e até imaginários - que, enquanto processo, resulta na existência do interdiscurso, uma espécie de memória do dizer. Assim, o não dito ou a ausência de determinadas temáticas no discurso da imprensa colaboram na constituição dos discursos dos sujeitos que consomem a informação veiculada e passam a assimilar tais conceitos e a reproduzi-los.

Para a análise desse discurso do não-dito, este trabalho considera as premissas da obra de Eni Puccinelli Orlandi (2007, p.53), para quem o dizer e silenciar andam juntos: "Há, pois, uma declinação política da significação que resulta no silenciamento como forma não de calar, mas de dizer 'uma' coisa, para não deixar dizer 'outras'. Ou seja, o silêncio recorta o dizer. Essa é sua dimensão política”.

Segundo Orlandi, as palavras carregam silêncio. E esse silêncio é promovido de forma intencional pelo locutor, criando sentidos: “Assim, quando dizemos que há silêncio nas palavras, estamos dizendo que elas são atravessadas de silêncio: elas produzem silêncio; o silêncio "fala" por elas; elas silenciam (ORLANDI, 2007, p. 14)."

No pensar da autora, é preciso entender que os caminhos da significação não são únicos, fáceis de serem percebidos ou medidos. Os sentidos são estruturados de forma dispersa e podem surgir em diferentes direções, materializando-se de diferentes maneiras, como na forma de silêncio. Ela apresenta dois tipos diferentes de silêncio possíveis no discurso e que também ajudam a compor as mensagens que os textos pretendem passar, conforme a seguir (ORLANDI, 2007, p. 24):

a) o silêncio fundador, aquele que existe nas palavras, que significa o nãodito e que dá espaço de recuo significante, produzindo as condições para significar; e b) a política do silêncio, que se subdvide em: bI) o silêncio constitutivo, o que nos indica que para dizer é preciso um não-dizer (uma palavra apaga necessariamente outras palavras) e bII) o silêncio local, que se 
refere à censura propriamente (àquilo que é proibido dizer em uma certa conjuntura).

Nessa esteira, o silêncio como o "não-dito" discursivamente, contribui para deixar mais claros alguns elementos que não aparecem na análise do conteúdo linguístico. Assim, com base nas considerações sobre imprensa, discurso e silêncio, analisaremos o corpus selecionado, composto por reportagens publicadas no jornal $A$ Gazeta entre os anos de 1988 e 2003.

\section{O DITO E O NÃO-DITO SOBRE OS QUILOMBOLAS}

Para que seja feita a análise do corpus é necessário, em primeiro lugar, contextualizar o veículo responsável pela publicação. Conforme registra o pesquisador José Antonio Martinuzzo (2008), a imprensa capixaba apresenta um histórico de envolvimento político das direções dos jornais. Para o autor, a grande mídia no estado sempre se colocou como parceira da implantação dos grandes projetos industriais.

E a história de A Gazeta, mais antigo jornal em circulação no estado do Espírito Santo, fundado em 1928, também seguiu essa lógica. Sua intensa relação política está registrada no âmbito de seu próprio desenvolvimento, tendo os seus proprietários desde o início marcado presença no campo político. De acordo Martinuzzo (2005):

O grupo ligado a Carlos Lindenberg [...] criou uma sociedade e pediu para uma terceira pessoa, Alfredo Alcure, representante do Partido Social Democrata (PSD) e amigo de Eleosippo da Cunha (UDN), para comprar o jornal. Anos depois, A Gazeta foi transferida para a sociedade criada. Os membros dessa sociedade, aos poucos, foram vendendo as suas partes, as quais foram sendo adquiridas por Carlos Lindenberg que, em 1948, já governador, acabou sendo o maior acionista do jornal (p. 78).

Além de ter servido como suporte discursivo do partido político de seu proprietário, o Partido Social Democrático (PSD), seguiu também apoiando os partidos aliados de Lindenberg, como a Aliança Renovadora Nacional (Arena). Essa relação foi mantida durante o período da ditadura, conforme explica Martinuzzo (2008):

O jornal A Gazeta foi fundado em 1928, período do boom da cafeicultura no Estado. No final da década de 1940, o impresso foi comprado pela família Lindenberg. Como Carlos Lindenberg foi, por duas vezes, eleito governador do estado (1947-1950 e 1959-1962), o jornal passou a ser porta-voz de seu partido político [...]. Em 1964, início do regime militar, o general Darcy Pacheco de Queiroz assumiu o posto de editor-chefe de A Gazeta. Ele era irmão da esposa de Carlos Lindenberg, e de Eugênio Queiroz, diretor- 
comercial da empresa. Assim, seguiu-se o histórico de envolvimento político do jornal, agora sob as regras da ditadura (p.179).

Importante frisar que o periódico integra um conjunto de 20 negócios na área de comunicação desse grupo empresarial, entre esses quatro emissoras de TV aberta afiliadas à Rede Globo. Circulando em todo o Espírito Santo, parte da Bahia e de Minas Gerais e nas cidades do Rio de Janeiro, São Paulo e Brasília, o jornal A Gazeta "discursa" para um público preponderantemente formado pelas classes A, B e C e adota, por esse motivo, uma linha mais conservadora, tanto na forma quanto no conteúdo (MARTINUZZO, 2005).

A amostra que será analisada foi construída obedecendo critérios temporais e temáticos. Como recorte temporal, optou-se pelo período compreendido entre outubro de 1988 (data da promulgação da Constituição Federal que reconheceu o direito ao território às comunidades quilombolas) e dezembro 2003 (ano da publicação do Decreto n. 4.887). O levantamento dos dados foi realizado entre os meses de maio e julho de 2017 por meio do uso do software The Shell, sistema de busca que gerencia todo banco de dados digitais do grupo de comunicação ao qual o jornal está ligado.

A busca eletrônica dos textos efetivou-se por meio do uso das seguintes palavras-chave e suas respectivas variações de gênero e número: quilombo, quilombola, remanescente, escravo e negro. A partir de todo material levantado, foram selecionadas as publicações em que as palavras quilombos ou quilombolas (e suas variações) foram citadas.

\section{Aspectos gerais do noticiário}

A partir dessa filtragem, foram registradas somente 14 ocorrências nas quais quilombo ou quilombola figuraram direta ou indiretamente nos textos ao longo dos 15 anos analisados. Desse total, os quilombolas foram tema central em oito oportunidades apenas, os quais serão objeto de análise específica durante a realização da pesquisa.

Um fato que deve ser destacado é que o direito ao reconhecimento e à titulação dos territórios das comunidades quilombolas só foi abordado de forma direta em uma única oportunidade, na última reportagem do período analisado, publicada em 2003. A referência a esse direito nessa oportunidade era presumível, pois o texto em questão aborda o lançamento de um nova ação do governo federal proporcionada pelo decreto $\mathrm{n}$. 4.887/03, embora não mencione a lei diretamente, veiculada na editoria "Brasil", CSOnline - Revista Eletrônica de Ciências Sociais, Juiz de Fora, n. 23 (2017), pp. 100-119. 
certamente elaborada a partir de informações de agências. Ou seja, não partiu do próprio jornal.

Em uma outra ocorrência um pequeno trecho aborda o reconhecimento e titulação não como direito ou política de estado. Nessa reportagem de duas páginas publicada no Caderno de Cultura do dia 16 de agosto de 1998, cuja abordagem da matéria se dá a partir da perspectiva de preservação de costumes, a possibilidade de reconhecimento é mencionada, resumindo-se ao seguinte enunciado: "O trabalho antropológico realizado por Osvaldo Martins de Oliveira foi enviado para a fundação Cultural Palmares, em Brasília, em abril deste ano. A partir dele, Retiro do Mangaraí poderá ser reconhecido como um remanescente de quilombo pelo governo federal e ganhar uma titulação coletiva, dando posse comum a todos habitantes". O trabalho mencionado é uma dissertação de mestrado da fonte da matéria e essa titulação não é apresentada pelo jornal como um direito constitucional. Fala-se apenas na possibilidade do governo reconhecer a partir de um trabalho individual de um pesquisador.

A legislação que garante o direito às comunidades (artigo constitucional, decretos e instrumentos normativos editados pelo legislativo e executivo) também não figura em nenhuma parte do jornal ao longo de 15 anos. Quer dizer, o direito constitucional não aparece, o que colabora no enfraquecimento da demanda das comunidades. Os jornais geralmente utilizam a CF quando desejam cobrar das autoridades determinadas questões, como saúde e educação, mas essa estratégia não é verificada quando se trata do direito territorial das comunidades negras.

Percebe-se que o jornal enfatiza as fragilidades das comunidades, pontos negativos, o que pode ser entendido como reividincação de melhorias, mas a titulação que pode alterar a estrutura fundiária, mexendo com a propriedade privada -, é completamente silenciada na cobertura analisada.

Essa ausência do direito ao reconhecimento e titulação de territórios quilombolas representa a aplicação da política do silêncio, o silenciamento, pois “[...] como o sentido é sempre produzido de um lugar, a partir de uma posição do sujeito - ao dizer, ele estará, necessariamente, não dizendo 'outros sentidos'. Isso produz um recorte necessário no sentido. Dizer e silenciar andam juntos" (ORLANDI, 2007, p. 53). Ou seja, fala-se de várias coisas para não se abordar a mais polêmica das questões sob a ótica capitalista: a possibilidade de modificação na propriedade privada.

Nesse conjunto de textos analisado ainda é possível registrar o apagamento das comunidades quilombolas em uma perspectiva histórica. As oito reportagens citam CSOnline - Revista Eletrônica de Ciências Sociais, Juiz de Fora, n. 23 (2017), pp. 100-119. 
somente quatro comunidades diferentes (Boa Esperança e Cacimbinha [município de Presidente Kennedy], Retiro [Santa Leopoldina] e Espírito Santo [São Mateus], sendo esta última denominada de o "último quilombo"), mas não há conexão entre as matérias nem referência direta à existência de um número relavante de territórios no estado.

Os textos pautam de forma isolada cada grupo, abordando uma comunidade específicamente em cada edição. Há repetição e alternância entre as comunidades abordadas nos textos, ficando restrito a três municípios capixabas em que haveria esse tipo de grupo social no estado: 1992 (Cacimbinha e Boa Esperança); 1994 (Espírito Santo); 1998 (Retiro); 1999 (Espírito Santo); 2000 (Cacimbinha e Boa Esperança); e 2002 (Espírito Santo).

Essa forma de abordagem ignora a existência de mais de 50 comunidades quilombolas distribuídas em diferentes cidades do estado, conforme registra Oliveira (2011). Esse tipo de enquadramento reforça a ideologia da democracia racial, em que o equilíbrio racial e a miscigenação coloca a escravidão como algo do passado, as comunidades quilombolas como algo raro e exótico, existindo somente no imaginário como monumento cultural (OLIVEIRA, 2016). Uma espécie de registro do nosso passado que não mais existe.

E van Dijk (2008) afirma que geralmente o discurso hegemônico procura enfatizar o racismo, a herança escravagista como algo distante, pois "[...]lemos muito pouco sobre a situação atual dos grupos minoritários do país. E, como no caso de quase todo discurso oficial, na política e na mídia, isto é definido como uma 'coisa do passado"” (p.22).

Conforme o trecho extraído de matéria publicada em 17 de maio de 1992, sob o título "Famílias negras vivem em quilombos no sul", em que em uma retranca denominada "Quilombo" o jornalista registra o seguinte enunciado, tendo como fonte um historiador: "Maciel diz que o processo imigratório foi acabando com os grupos, fazendo com que os negros migrassem para bairros nas proximidades das sedes dos municípios."

Em outra reportagem publicada em 22 de dezembro de 1994, logo no primeiro parágrafo do texto o jornal decreta: “A 18 quilômetros do centro de São Mateus, no Norte do Estado, há uma comunidade formada por cerca de 40 famílias de negros, remanescentes de escravos, que formam o último quilombo da região".

E, ainda, ao ignorar a existência de um vasto universo de comunidades, o jornal colabora na construção do discurso que atualmente é utilizado pelos grupos contrários à CSOnline - Revista Eletrônica de Ciências Sociais, Juiz de Fora, n. 23 (2017), pp. 100-119. 
titulação: o de que as terras expropriadas pelos imigrantes europeus e pelas grandes empresas estavam "vagas", negando a presença das comunidades rurais negras. Segundo a teoria da Análise do Discurso, para construir os seus enunciados o enunciador faz uso da memória do dizer, do interdiscurso. Desse modo, o que o jornal ajudou a sedimentar no passado aparece nos enunciados atuais produzidos para combater a conquista dos direitos dos quilombolas.

\section{CONSIDERAÇÕES FINAIS}

Os meios de comunicação ocupam papel central na formação da opinião das pessoas, especialmente nas sociedades contemporâneas agrupadas em contingentes populacionais enormes. Isso favorece a atuação da mídia de massa. E o jornalismo, como campo estruturado de forma a atuar na promoção de ideias com grande capilaridade (CASTELLS, 2015), é fundamental ao processo de construção de sentidos.

E os grupos minoritários como as comunidades quilombolas são os mais fragilizados no acesso ao campo do jornalismo e ficam em desvantagem no processo discursivo promovido pela imprensa, pois há privilégios às ideologias hegemônicas (MARTINS, 2016).

O grande problema está justamente na falta de acesso dessas minorias ao campo jornalístico. Conforme o pensar de Wilson Gomes e Rousiley Maia (2008), na contemporaneidade a esfera pública é dominada ou pré-estruturada pelos meios de comunicação. E como é nesse universo que temas de interesse público são colocados em pauta e debatidos por agentes públicos e privados, contribuindo na formação da opinião pública e em parte ao tensionamento do Estado para o atendimento dos anseios populares, a forma de abordagem da imprensa sobre a titulação de territórios quilombolas torna-se relevante para que essa política seja efetivada. Molotch e Lester (1974;1993, apud TRAQUINA, p. 22) enfatizam que “[...] o conteúdo das concepções de um indivíduo da história e do futuro da sua comunidade vem a depender dos processos através dos quais os acontecimentos públicos se transformam em recurso do discurso nos assuntos públicos".

A despeito da polêmica que o tema suscita, a análise do corpus da pesquisa, constatou o apagamento dos territórios quilombolas das páginas do jornal A Gazeta. Para ter-se ideia do problema: entre 1988 e 2003 somente oito textos publicados nesse periódico relataram a existência de comunidades remanescentes de quilombos no CSOnline - Revista Eletrônica de Ciências Sociais, Juiz de Fora, n. 23 (2017), pp. 100-119. 
Espírito Santo, limitando-se a quatro comunidades em um universo que pode passar de 50.

Se a objetividade e a busca da imparcialidade defendidas no campo jornalístico fossem aplicadas, especialmente a partir do emprego dos critérios de noticiabilidade, a relevância do tema e os diversos acontecimentos ao longo dos 15 anos atenderiam a esses critérios e as comunidades teriam entrado na pauta do jornal com mais frequência.

A partir dessa cobertura, o discurso do jornal reproduziu a ideologia sedimentada desde o fim da escravidão de que a luta e resistência das comunidades negras a partir da organização social de quilombos ficou no passado, não existindo mais. E esse enunciado é o empregado pelos agentes que hoje se opõem à concretização do direito aos territórios das comunidades quilombolas, conforme prevê a Constituição Federal.

Além de não abordar a existência de grande número de comunidades no estado, o discurso no jornal promove o silenciamento do direito ao território dos quilombolas ao não abordar a existência de leis que dão suporte a esse benefício às comunidades. Com base nesse fenômeno, o jornal, ao abordar questões culturais e até mesmo sociais das comunidades, deixa de falar sobre a questão territorial. Conforme Orlandi (2007), essa é também uma forma de produção de sentido, de discurso.

Além disso, a construção dos enunciados que fazem opção por determinadas informações em detrimento de outras (falam de tudo menos da titulação) materializam ainda a ideologia liberal da propriedade privada. Essa ideologia foi consolidada a partir da revolução burguesa a pela propagação do enunciado básico que colocava "a propriedade privada como um direito natural". Dessa forma, tal pensamento foi consolidado sócio-historicamente e até hoje figura como o preceito básico do capitalismo, sendo a titulação dos territórios quilombolas uma ameaça direta a essa premissa.

No período observado, a parca cobertura do jornal analisado limitou-se a tratar de questões ligadas à cultura e a alguns problemas estruturais, passando ao largo de assuntos de real interesse daquelas comunidades como a luta pelo reconhecimento e demarcação de seus territórios.

\section{REFERÊNCIAS}


ANDRADE, Patrícia Gomes Rufino. A educação do negro na comunidade de Monte Alegre-ES em sua prática de desinvibilização da cultura popular negra. 2007. Dissertação (Mestrado em Educação) - Programa de Pós-graduação em Educação, Universidade Federal do Espírito Santo, Vitória, 2007.

ARRUTI, José Maurício Andion. A emergência dos "remanescentes": notas para diálogo entre indígenas e quilombolas. Revista Mana. Rio de Janeiro, v. 03, n. 02, out.1997.

BOURDIEU, Pierre. O poder simbólico. Rio de Janeiro: Bertrand Brasil, 2000.

Questões de sociologia. Lisboa: Fim do Século, 2003.

Sobre a televisão. Rio de Janeiro: Jorge Zahar Editora, 1997.

BRANDÃO, Helena H. Nagamine. Introdução à análise do discurso. São Paulo: Unicamp, 2012.

BRASIL. Constituição da República Federativa do Brasil. Brasília/DF: Senado Federal, 1988. 292 p.

CASTELLS, Manuel de. O poder da comunicação. São Paulo: Paz e Terra, 2015.

CHARAUDEAU, Patrick. Discurso político. São Paulo: Contexto, 2006.

FERREIRA, Simone Raquel Batista. "Donos do lugar": a geo-grafia negra e camponesa do sapê do norte-ES. Revista Geografares (Programa de Pós-Graduação em Geografia da Universidade Federal do Espírito Santo). Vitória, n. 08, 2010. Disponível em: <http://www.periodicos.ufes.br/geografares/article/viewFile/1298/980 >. Acesso em: 21 set. 2016.

GINZBURG, Carlo. Relações de força: história, retórica, prova. São Paulo: Companhia das Letras, 2002.

GOMES, Wilson; MAIA, Rousiley. Comunicação e democracia: problemas e perspectivas. São Paulo: Paulus, 2008.

HOHLFELDT, Antônio; MARTINO, Luiz C.; FRANÇA, Vera Veiga. Teorias da Comunicação: conceitos, escolas e tendências. Rio de Janeiro: Vozes, 2005.

MACIEL, Cléber. Negros no Espírito Santo. Vitória: Secretaria de Produção e Difusão Cultural/Ufes, 1994.

MARTINS, André Ricardo Nunes. "Imprensa, minorias e análise do discurso: um espaço de construção da democracia". Cadernos de Linguagem e Sociedade. Brasília, v. 17, n. 2, 2016. p. 26-42 <http://periodicos.unb.br/index.php/les/article/view/1244>. Acesso em: 02 jul. 2017.

MARTINUZZO, José Antônio (Org.). Impressões capixabas: 165 anos de jornalismo no Espírito Santo. Vitória: Departamento de Imprensa Capixaba, 2005. 
. (Org.). Quase 200 anos: a imprensa na história capixaba. Vitória: Departamento de Imprensa Capixaba, 2008.

OLIVEIRA, Osvaldo Martins. Comunidades quilombolas no Estado do Espírito Santo: conflitos sociais, consciência étnica e patrimônio cultural. Revista do Centro de Estudos Rurais (RURIS). Campinas, v. 05, n. 02, 2011. Disponível em: <https://www.ifch.unicamp.br/ojs/index.php/ruris/article/view/1469/986>. Acesso em: 20 fev. 2017.

(Org.). Direitos quilombolas \& dever de Estado em 25 anos da Constituição

Federal de 1988. Rio de Janeiro: Associação Brasileira de Antropologia, 2016.

ORLANDI, Eni Puccinelli. As formas do silêncio: no movimento dos sentidos. Campinas: Unicamp, 2007.

PÊCHEUX, Michel. O discurso: estrutura ou acontecimento. Campinas: Pontes Editora, 1990.

SILVA, João Marques da. De onde nois vei, prá onde nois vai? 2015. Dissertação (Mestrado em História) - Pós-graduação em História, Universidade Federal de Goiás, Goiás, 2015.

SANTOS, Simone Ritta dos. Comunidades Quilombolas: as lutas por reconhecimento de direitos na esfera pública brasileira. Porto Alegre: EdiPucRS, 2014.

TRAQUINA, Nelson. O estudo do jornalismo no século XX. São Leopoldo: Unisinos, 2005.

VAN DIJK, Teun A. Racismo e discurso na América Latina. São Paulo: Contexto, 2008.

WOLF, Mauro. Teorias da comunicação. Lisboa: Presença, 2003. 